\title{
Optimal Supercapacitor Energy Storage System Sizing for Traction Substations
}

\author{
Ugis Sirmelis ${ }^{1}$, Janis Zakis ${ }^{1}$ \\ ${ }^{1}$ Institute of Industrial Electronics and Electrical \\ Engineering \\ Riga Technical University \\ Riga, Latvia \\ ugis.sirmelis@gmail.com,janis.zakis@ieee.org
}

\author{
Linards Grigans ${ }^{2}$ \\ ${ }^{2}$ Laboratory of Power Electronics \\ Institute of Physical Energetics \\ Riga, Latvia \\ Linards.Grigans@gmail.com
}

\begin{abstract}
In this paper authors present a method for optimal sizing of supercapacitor (SC) energy storage system (ESS) for braking energy recovery in tram network. The method is applicable for segmented tram networks with radial feeding topology and a stationary storage system installed in traction substation. The method is demonstrated for one traction substation of Riga public transport network.
\end{abstract} sizing;

Keywords-supercapacitor; energy storage; braking energy;

\section{INTRODUCTION}

A well known method to reduce the energy consumption in tram systems is equipping trams with traction converters that enable braking energy recuperation back to the feeding line. However, this ensures only partial utilization of braking energy, because often there are situations when there is no other vehicle nearby that could consume this energy. In cases like this, recuperated energy is dissipated in tram brake resistors. To maximize the efficiency of recuperated energy utilization three technical solutions can be used: (1) equipping traction substations with bidirectional rectifiers that transfer recuperated energy back to AC grid, (2) equipping trams with on-board energy storage systems, (3) installing stationary ESS in traction substation.

Research described in this paper is focused on stationary ESS. The main advantage of this technical solution over the on-board ESS is its ability to serve for more than just one tram. The whole braking energy can be saved (excluding losses in ESS interface converter and SCs and contact lines) if the rated power and the rated energy capacity of stationary ESS are larger than the total braking power and braking energy of the maximum number of trams running within the feeding zone of traction substation. However, the situation when all trams simultaneously or sequentially brake and no one accelerates is very rare, so there is no sense in such a sizing of the ESS to capture all regenerated energy. The investigation of the influence of ESS with limited power capability and energy capacity on the energy savings is done in [1], [2]. The results obtained in these papers show only how much energy can be saved with variously sized stationary
ESS, however it is not shown how to choose ESS parameters to maximize its profit.

In this paper authors offer a method that allows sizing of ESS in a way that the profit from ESS operation is maximized in its operation time, which is assumed to be 10 years. The method is used to choose the optimal power and energy capacity values for ESS for traction substation №8 in Riga city.

\section{RECOVERABLE ENERGY ESTIMATION}

\section{A. Case Study}

In many European cities, including Riga, tram feeding infrastructure has radial architecture as it is shown in Fig. 1. Feeding zone of each traction substation is divided in several sections that are mutually separated by section isolators. Each section is fed by individual feeding cable, which means that energy exchange between trams located in different sections, can happen only through substation and only if these sections belong to one substation.

This study as an example uses feeding zone of traction substation №8 of Riga public electric transport network. Particular substation is feeding a part of tram line №11. The length of this part is $3.8 \mathrm{~km}$ and it has 10 stops in each direction. It is assumed that only trams consisting of two coupled T3A tram cars are running on this line. Example of experimentally measured power diagram of such tram is shown in Fig. 2.

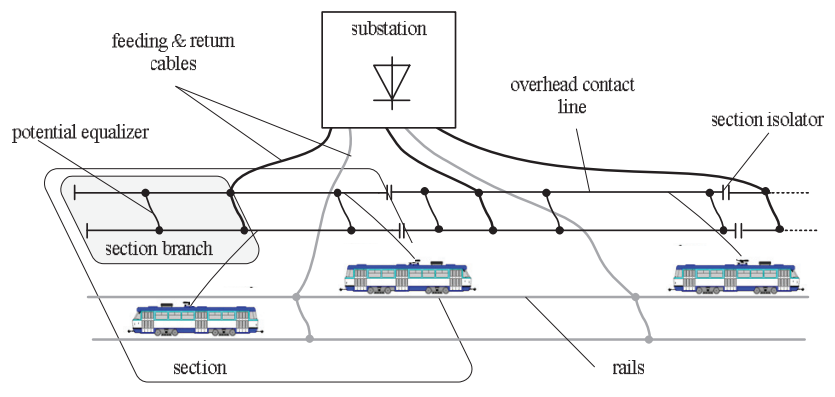

Fig. 1. Radial tram feeding network architecture. 


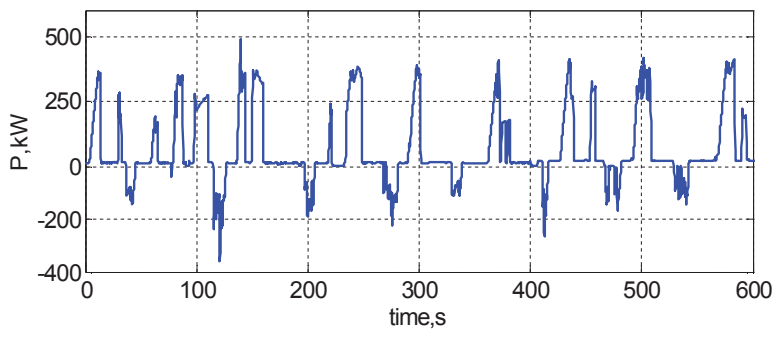

Fig. 2. T3A tram power diagram.

\section{B. Stochastic Modeling Method}

For supercapacitor battery sizing first it is necessary to obtain the relationship of how the recoverable braking energy amount depends on ESS energy capacity $E_{\max }$ and power capability $P_{\max }$. This relationship can be obtained by stochastic modeling method described in [1].

Stochastic modeling method is based on experimentally measured tram power diagrams, which are used to synthesize combined power diagrams for different number of trams (one to six trams). Then for each synthesized power diagram the values of average recoverable power are calculated for different ESS energy capacity and power capability.

Then the timetable is used to calculate the durations for the situations when within the feeding zone of selected substation there are one, two etc. trams. Multiplying these time values by average recoverable power for corresponding number of trams, annual recoverable energy for particular substation is obtained as a function of $E_{\max }$ and $P_{\max }$.

\section{Example}

To estimate the amount of recoverable braking energy, first from the tram timetable the durations for the situations when within feeding zone of substation №8 there are one, two etc. trams are determined (Table I).

By applying the stochastic modeling method [1] the recoverable braking energy for substation №8 is obtained (Fig. 3). As can be seen in the Fig. 3, variation in $P_{\max }$ and $E_{\max }$ values in a range between $0-250 \mathrm{~kW}$ and $0-0.5 \mathrm{kWh}$, respectively, affects the amount of recovered energy significantly. Further increase of $P_{\max }$ and $E_{\max }$ values leaves more and more negligible effect on saved energy. Highlighted data points in the diagram will be used later, to show, how oversized ESS decreases the potential profit of installed device.

TABLE I.

\begin{tabular}{|c|c|c|c|}
\hline \multirow{2}{*}{$\begin{array}{c}\text { Number of trams } \\
\text { within substation } \\
\text { No8 feeding zone }\end{array}$} & \multicolumn{3}{|c|}{ Total time for each number of trams } \\
\cline { 2 - 4 } & Working days & Saturdays & Sundays \\
\hline 1 & $1.32 \mathrm{~h}$ & $1.33 \mathrm{~h}$ & $1.71 \mathrm{~h}$ \\
\hline 2 & $4.13 \mathrm{~h}$ & $6.65 \mathrm{~h}$ & $5.65 \mathrm{~h}$ \\
\hline 3 & $5.41 \mathrm{~h}$ & $5.40 \mathrm{~h}$ & $6 \mathrm{~h}$ \\
\hline 4 & $5.76 \mathrm{~h}$ & $3.30 \mathrm{~h}$ & $3.41 \mathrm{~h}$ \\
\hline 5 & $2.10 \mathrm{~h}$ & $1.15 \mathrm{~h}$ & $0.80 \mathrm{~h}$ \\
\hline 6 & $0.13 \mathrm{~h}$ & $0.10 \mathrm{~h}$ & $0 \mathrm{~h}$ \\
\hline
\end{tabular}

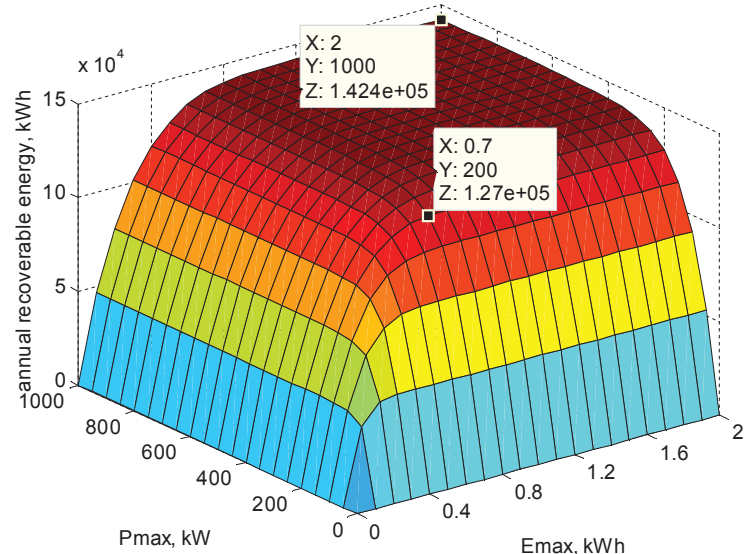

Fig. 3. ESS parameters effect on annual recoverable energy in substation №8 feeding zone.

\section{SUPERCAPACITOR BATTERY SIZING}

In this paper optimal ESS sizing is carried out assuming that SC lifetime is 10 years. Such an assumption is based on the information found in SC manufacturers technical literature [3],[4],[5]. Supercapacitors cycling with high current values leads to very rapid decrease of their capacitance and increase in series resistance and the end of SCs lifetime can be achieved in several days [6]. Therefore to ensure that the life time of SCs is at least 10 years, the maximum permissible SC charge/discharge current in this paper is limited to 100A. For more reasonable choice of SC maximum current, advanced SC aging model is required, which considers continuous values of SC current, voltage and temperature. Such a model is not provided by SC manufactures, but SC aging models analyzed in various scientific papers are incomplete and give questionable results for wider SC temperature and voltage range[6],[7],[8].

\section{A. ESS Cost Estimation}

To find the optimal values for ESS power capability $P_{\max }$ and energy capacity $E_{\max }$, it is not enough if we have the diagram of annual recoverable energy (Fig. 3). Also the ESS cost as a function of its parameters $E_{\max }$ and $P_{\max }$ is needed.

The ESS cost includes the price of IGBT transistors and their drivers, filter capacitors, inductors, cooling system, mounting enclosure, control system, SC voltage balancing and monitoring system, radio frequency filters, current sensors, contactors, cables, busbars and other assembly materials and production costs. Since the price of ESS forming components are highly dependent on the volume, it is impossible to clearly evaluate the total costs. However, an approximate ESS price estimation can be made by assuming that the total ESS price is proportional to the number of SCs. It is assumed that the price of SCs is half of the ESS price, similar assumption is done in [9]. Thus it is necessary to find for each $P_{\max }$ and $E_{\max }$ combination corresponding number of SCs. This number can be derived from the ESS energy capacity and power capability 
expressions. The ESS energy capacity can be calculated as follows:

$$
E_{\text {max }}=N \cdot \frac{C \cdot V_{\max }^{2}}{2} \cdot\left(1-d^{2}\right),
$$

where: $N$ - number of SCs;

$C$ - capacitance of single SC cell, [F];

$V_{\max }$ - single SC cell maximum voltage, [V];

$d$ - SC depth of discharge.

The ESS power capability is calculated as follows:

$$
P_{\max }=N \cdot d \cdot V_{\max } \cdot I_{\max },
$$

where $I_{\max }$ is the chosen maximum current for single SC cell.

From (1) and (2) the minimal number of SCs $N$ and SC discharge depth $d$ can be obtained as:

$$
\begin{gathered}
N=\frac{E_{\max }}{V_{\max }^{2} \cdot C}+\sqrt{\left(\frac{E_{\max }}{V_{\max }^{2} \cdot C}\right)^{2}+\left(\frac{P_{\max }}{V_{\max } \cdot I_{\max }}\right)^{2}}, \\
d=\sqrt{\left(\frac{E_{\max } \cdot I_{\max }}{P_{\max } \cdot V_{\max } \cdot C}\right)^{2}+1}-\frac{E_{\max } \cdot \mathrm{I}_{\max }}{P_{\max } \cdot V_{\max } \cdot C} .
\end{gathered}
$$

To find minimal SC discharge depth and number of SC cells as function of ESS parameters, calculations using (3) and (4) were carried out for previously discussed $P_{\max }$ and $E_{\max }$ values and the results are shown in Fig. 4 and Fig.5. In this case we assumed that $V_{\max }=2.8 \mathrm{~V}$ and $C=3400 \mathrm{~F}$ which corresponds to the technical data of Maxwell K2 3400 supercapacitors.

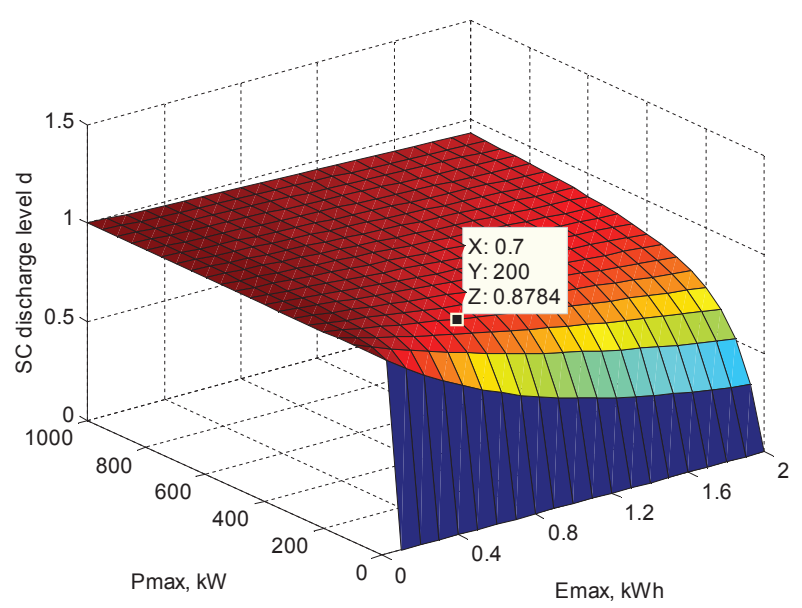

Fig. 4. Optimal SC discharge depth.

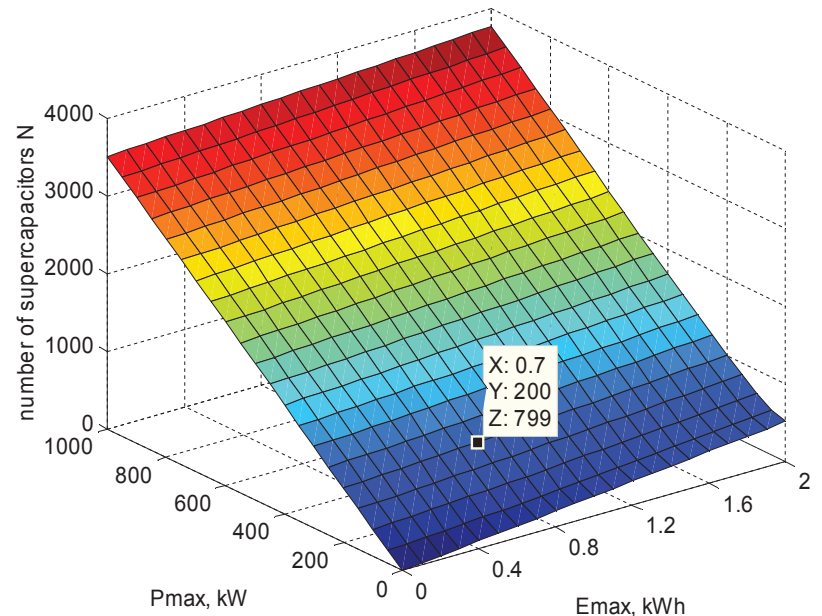

Fig. 5. Optimal number of supercapacitors for different $E_{\max }$ and $P_{\max }$.

In Fig. 4 it can be seen that ESS that ensures accumulation of almost all recuperated energy $\left(\mathrm{P}_{\max }>250 \mathrm{~kW}\right.$, $\mathrm{E}_{\max }>0.5 \mathrm{kWh}$ ) requires $\mathrm{SC}$ discharge depth $\mathrm{d}>0.7$.

Fig. 5 shows how the number of SCs should be chosen to ensure particular ESS power and energy parameters. Surface gradient in the $E_{\max }$ axis direction is much lower than gradient of $P_{\max }$ axis, which means that SCs power capability is the dominating parameter that determines the number of SCs in ESS.

The approximate ESS cost as a function of ESS power capability $P_{\max }$ and energy capacity $E_{\max }$ is obtained by multiplying the number of SCs cells with the price for one Maxwell K2 3400F cell (based on Mouser and Digikey electronic catalogues here this price is assumed to be €50) and then multiplying by two. The obtained ESS cost diagram is shown in Fig. 6.

Fig. 6 leads to similar conclusion that was made from Fig. 5 analysis - the price of ESS is mainly determined by its power capability.

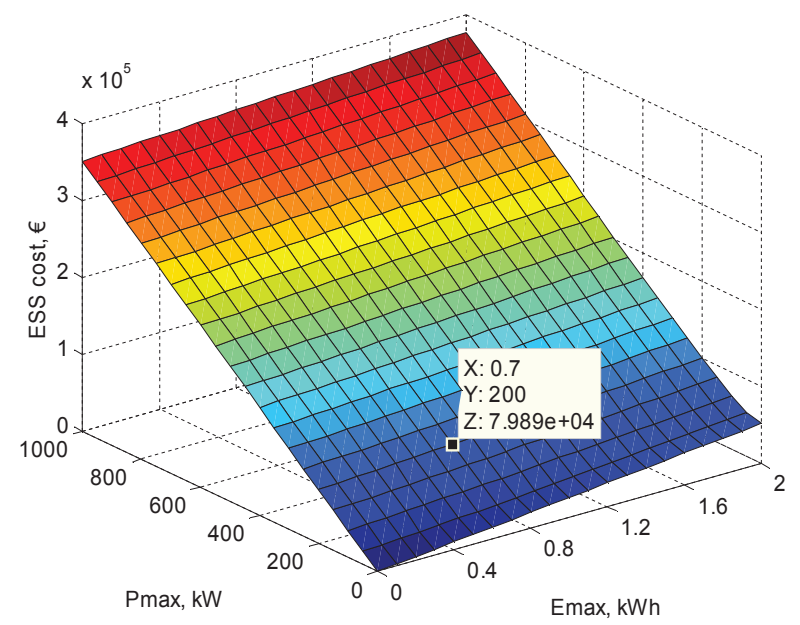

Fig. 6. ESS cost in Euros for different $E_{\max }$ and $P_{\max }$. 


\section{B. Profit Estimation}

Since typical lifetime for SCs according to manufactures is 10 years, then consequently, this could be a period during which the amount of recoverable energy will determine the ESS optimal parameters. If we assume the electricity price for $1 \mathrm{kWh}$ to be $€ 0.15$, then the value of recoverable energy for the ESS in feeding zone of substation №8 over 10 years period is as shown in Fig. 7.

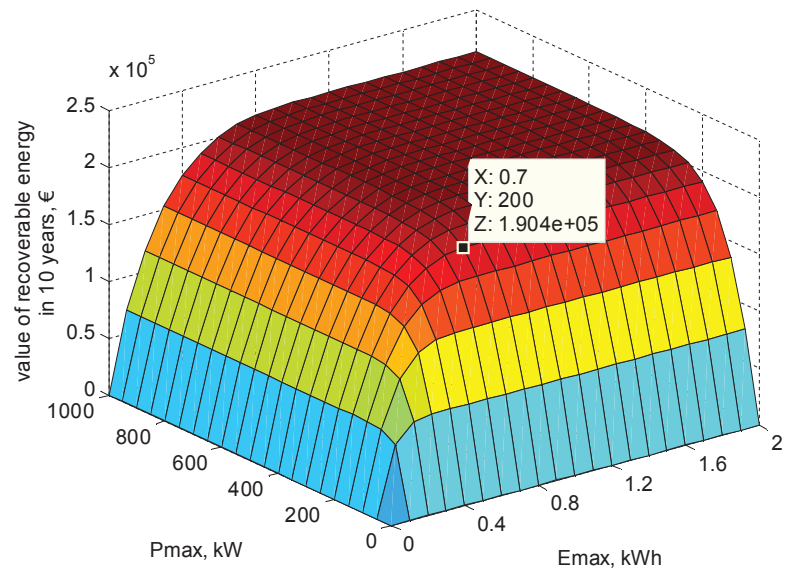

Fig. 7. Value of recoverable braking energy in 10 years for substation №8.

Then by subtracting the ESS cost diagram (Fig. 6) from this recoverable energy value diagram (Fig. 7), the profit diagram is obtained (Fig. 8).

The ESS power capability $\mathrm{P}_{\max }=200 \mathrm{~kW}$ and energy capacity $E_{\max }=0.7 \mathrm{kWh}$ values, which in Fig. 8 give the maximum profit of $€ 110000$, are the optimal ESS parameters. For the substation №8 according to Fig. 3 - Fig. 7 ESS would be formed of 799 cells with operation discharge level $d$ equal to 0.87 (Fig. 4). Initial financial investments for such a system is approximately $€ 80000$ and it would recover $127000 \mathrm{kWh}$ braking energy annually, which in 10 years period leads to $€ 190000$ savings.

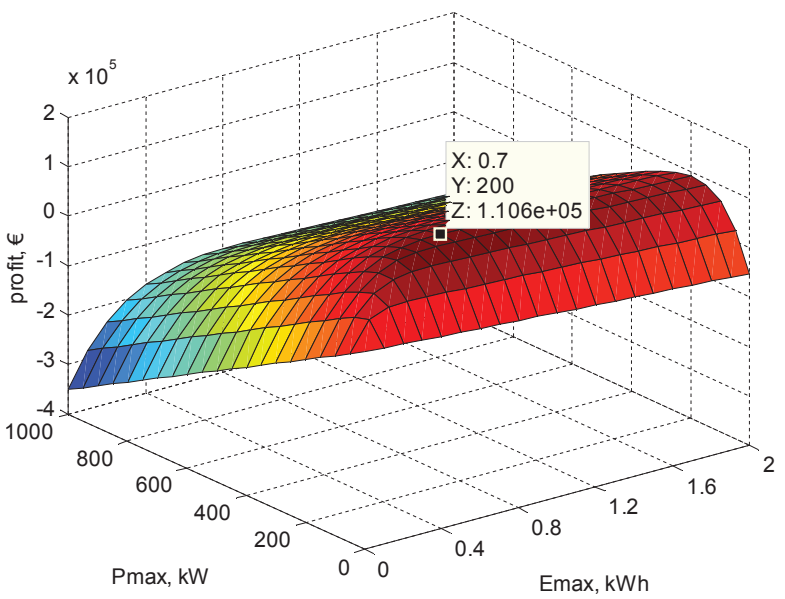

Fig. 8. ESS potential profit in 10 years for substation №8.
To demonstrate how oversized ESS decreases potential profit, highlighted point $\left(\mathrm{E}_{\max }=2 \mathrm{kWh}, \mathrm{P}_{\max }=1000 \mathrm{~kW}\right)$ in Fig. 3 can be used. ESS with such parameters would increase annually saved energy amount by $154000 \mathrm{kWh}$ if compared to optimal sized ESS, however, the cost of such ESS is almost 5 times higher, which leads to negative profit $(€ 164300)$ in 10 years period.

\section{DISCUSSION}

Excluding previously mentioned discussions on SC lifetime, losses in system and ESS price, three other factors that may influence the accuracy of proposed method can be discussed: (1) discounted value of money, (2) electricity price increase, (3) changes in number of trams running the corresponding line or even changes of tram models.

\section{CONCLUSIONS}

The ESS sizing method presented in this paper shows that it is more profitable to choose ESS with power and energy capacity parameters that do not provide recovery off all recuperated energy. In the case of Riga traction substation №8, only $89 \%$ of energy wasted in brake resistors is saved using ESS that is sized with the proposed method.

Typical SC discharge depth most often is higher than 0.5 that is usually mentioned in literature, which means that theoretical ESS energy capacity is not fully utilized. In the case studied in this paper optimum discharge depth is 0.87 .

Although SCs are traditionally viewed as energy sources that have very high power capability, but limited energy capacity, this research shows that number of SCs needed to ensure optimal sized ESS is mainly determined by SCs power capability.

\section{REFERENCES}

[1] L. Grigans and L. Latkovskis, "Estimation of the power and energy requirements for trackside energy storage systems," in 13th European Conference on Power Electronics and Applications EPE 09, Spain, Barcelona, 2009, pp. P1-P7.

[2] L. Latkovskis and L. Grigāns, "Estimation of the untapped regenerative braking energy in urban electric transportation network," in 13th Power Electronics and Motion Control Conference EPE-PEMC 2008, Poznan, Poland, 2008, pp. 2089-2093.

[3] "Product Guide - BOOSTCAP Ultracapacitors - Doc. No. 1014627.1," Maxwell Technologies, Inc., 2009.

[4] "K2 2.85V/3400F Cell Datasheet." [Online] - Available: http://www.maxwell.com.

[5] "iCAP 3000F 2.7V Cell Datasheet." [Online] - Available: http://www.ioxus.com.

[6] P. Kreczanik, P. Venet, A. Hijazi, and G. Clerc, "Study of Supercapacitor Aging and Lifetime Estimation According to Voltage, Temperature, and RMS Current," IEEE Trans. Ind. Electron., vol. 61, no. 9, pp. 4895-4902, Sep. 2014.

[7] "UltraCap Double Layer Capacitors, A New Energy Storage Device for Peak Power Applications.” EPCOS, Product Profile-2001.

[8] D. Linzen, S. Buller, E. Karden, and R. W. De Doncker, "Analysis and evaluation of charge-balancing circuits on performance, reliability, and lifetime of supercapacitor systems," IEEE Trans. Ind. Appl., vol. 41, no. 5, pp. 1135-1141, 2005.

[9] H. Hõimoja, "Energy Efficiency Estimation and Energy Storage Calculation Methods for Urban Electric Transportation," Phd Thesis, Tallinn University of Technology, Tallin, Estonia, 2009.

This is a post-print of a paper published in Proceedings of the 2015 IEEE 5th International Conference on Power Engineering, Energy and Electrical Drives (POWERENG) [http://dx.doi.org/10.1109/PowerEng.2015.7266383] and is subject to IEEE copyright. 